\section{$\underset{\substack{\text { hommes } \\ \text { \& migrations }}}{ }$}

\section{Hommes \& migrations}

Revue française de référence sur les dynamiques

migratoires

\section{$1294 \mid 2011$}

L'intégration en débat

\title{
Laurence Cosse, Les Amandes amères
}

Paris, Gallimard, 2011, 220 pages, 16,90 euros

\section{Élisabeth Lesne}

\section{Q OpenEdition \\ 1 Journals}

\section{Édition électronique}

URL : http://journals.openedition.org/hommesmigrations/609

DOI : 10.4000/hommesmigrations.609

ISSN : 2262-3353

\section{Éditeur}

Musée national de l'histoire de l'immigration

\section{Édition imprimée}

Date de publication : 1 novembre 2011

Pagination : 148

ISSN : 1142-852X

\section{Référence électronique}

Élisabeth Lesne, «Laurence Cosse, Les Amandes amères », Hommes \& migrations [En ligne], 1294 |

2011, mis en ligne le 29 mai 2013, consulté le 22 septembre 2020. URL : http://

journals.openedition.org/hommesmigrations/609; DOI : https://doi.org/10.4000/hommesmigrations. 609

Ce document a été généré automatiquement le 22 septembre 2020.

Tous droits réservés 


\title{
Laurence Cosse, Les Amandes amères
}

Paris, Gallimard, 2011, 220 pages, 16,90 euros

\author{
Élisabeth Lesne
}

\section{RÉFÉRENCE}

Laurence Cosse, Les Amandes amères, Paris, Gallimard, 2011, 220 pages, 16,90 euros

“'Il faudrait vraiment que vous sachiez lire, laisse échapper Édith. Vous ne voulez pas que je vous apprenne?

- D'accord', dit Fadila en la regardant dans les yeux."

1 Lorsqu'elle fait cette proposition à sa femme de ménage, une Marocaine de 65 ans, Édith ignore les difficultés qui l'attendent : plus on apprend tard, plus l'apprentissage est ardu. Il faut compter deux ans pour une personne jeune, dix pour les plus âgées, la "rassurera" plus tard une spécialiste.

2 Avant de s'interroger sur la méthode à employer, Laurence Cossé montre le désarroi permanent des analphabètes : tout courrier est une menace, le bus est privilégié par rapport au métro - au moins on voit où l'on est, tandis que le nom des stations est incompréhensible. Les chiffres aussi gardent leur mystère : comment retenir tous les codes, les numéros de téléphone, comment comparer les prix?

3 Très vite, Édith va revoir à la baisse ses objectifs : il faudra trois mois et demi pour que Fadila sache écrire son prénom - "un chemin de rien du tout considérable". Et encore, rien n'est gravé dans le marbre, elles recommencent inlassablement : les voyelles, les consonnes, en partant des mots les plus utiles, le nom, l'adresse, les lignes de RER..., mais pas sûr que Fadila comprenne comment se combinent les lettres. Lire semble moins ardu qu'écrire : "L'échec est fugitif, on passe tout de suite à autre chose."

4 Le découragement menace parfois Édith. Mais le lecteur, lui, ne se lasse pas, même si l'apprentissage fastidieux, car fait de répétitions, est décrit par le menu : il espère que le déclic se produise.

5 Au fil des jours - et c'est là l'autre intérêt de ce roman - , Fadila livre peu à peu des fragments de son histoire. Une histoire dure, âpre, qui explique qu'elle soit “Amère. 
Stoïque. Déchirée. Brutale. Pas à une contradiction près". Elle ne paraît joyeuse et pleine d'entrain que pendant les séances d'étude. Sinon, elle se bat contre l'adversité : la recherche d'un logement; des vacances au Maroc où elle est toujours malade ; trois enfants qu'elle juge ingrats, surtout ses filles :

' $J$ ' pas d'chance mes enfants. Mon fils j' demande rien, il a une femme, c'est pas ma

fille, j' laisse tranquille. Les filles, c' pas pareil. Chez nous au Maroc, les filles ils doivent tout faire pour leur mère."

Mais elle jubile lorsque son fils déménage de Pantin à "Maison de la fête", entendez "Maisons-Lafitte": "C' la Côte d'Azur! Ils sont bien! Y a pas d' les Noirs, pas d' les Arabes."

Dans cette langue pleine d'élisions et de confusion des genres que Laurence Cossé essaie de traduire fidèlement - elle s'est inspirée d'une expérience personnelle -, Fadila exprime aussi son avis sur l'actualité. Elle s'enflamme à la victoire des Bleus à la demifinale de la Coupe du monde de football; elle se réjouit quand Nicolas Sarkozy l'emporte sur Ségolène Royale: 'Lui c' un homme. C' mieux un homme il est président"... Ce que d'ailleurs beaucoup de Français français pensent aussi !

7 Ce onzième roman de Laurence Cossé est un livre plein d'humanité, qui montre que l'intégration ne se fait pas toujours à la première génération et que l'immigration est souvent un déchirement, une perte de repères. 